\title{
What Can We Learn from Pathology?
}

\author{
From the Beginnings towards Radiosurgical Pathology ${ }^{1}$
}

\author{
György T. Szeifert ${ }^{\mathrm{a}}$, Douglas Kondziolka ${ }^{\mathrm{b}}$, L. Dade Lunsford $^{\mathrm{b}}$, \\ Zoltán Hanzély ${ }^{\mathrm{a}}$, István Nyáry ${ }^{\mathrm{a}}$, Isabelle Salmon ${ }^{\mathrm{c}}$, Marc Levivier ${ }^{\mathrm{c}}$

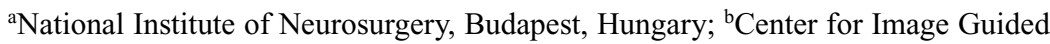 \\ Neurosurgery, Presbyterian University Hospital, Pittsburgh, Pa., USA and \\ ${ }^{\mathrm{c} C e n t r e ~ G a m m a ~ K n i f e, ~ U n i v e r s i t e ́ ~ L i b r e ~ d e ~ B r u x e l l s, ~ H o ̂ p i t a l ~ A c a d e ́ m i q u e ~ E r a s m e, ~}$ \\ Brussels, Belgium
}

\begin{abstract}
The term of radiosurgery signifies any kind of single application of ionizing radiation energy, in experimental biology or clinical medicine, aiming at the precise and complete destruction of chosen target structures containing healthy and/or pathological cells, without significant concomitant or late radiation damage to adjacent tissues. The goal of this radiosurgical pathology study is to explore the short- and long-term effects of high-dose ionizing radiation on neural tissue and its pathologies with histological, electron-microscopical, tissue culture and biological-biochemical methods. Radiosurgical pathology focuses its scope and microscope for histological, cell, genetic and molecular changes in the human body and experimental animals, or in tissue cultures and other in vitro experiments, generated by the ionizing radiation delivered from radiosurgical devices.
\end{abstract}

Copyright (C) 2004 S. Karger AG, Basel

\section{Background}

Radiosurgery, invented by Prof. Lars Leksell [1], has become a successful treatment modality in the neurosurgical realm during the past three decades. Since 1968, when the first patient was treated in Stockholm with the prototype Gamma Knife, more than two hundred thousand cases have already been operated on worldwide with the Gamma Knife. In addition to this, many patients were treated with other radiosurgical methods like linear accelerators or charged

${ }^{1}$ This paper is dedicated in honor of Professor Szabolcs Gomba, Department of Pathology, University Medical School of Debrecen, Hungary, for his 70th birthday. 
particle devices. Although the treatment indications and the number of treated patients has been increasing continuously, we know relatively little about pathological background of radiosurgery explaining radiobiology and pathophysiological mechanisms leading to therapeutic or undesired side effects. The future of radiosurgery beyond technical advancements will be built on better understanding of the biological basis of radiation, which will enable treatment of new disorders [2]. Regarding that huge clinical experience has already been accumulated in radiosurgery during the past three decades, it would be timely to process out systematically pathological fundamentals of the effect of single high-dose irradiation, to understand better radiobiology for radiosurgically treatable diseases. Medicine has been built from experience. As it had happened in the ancient times, clinical studies progressed much more ahead than the exploration of pathological-pathophysiological mechanisms of radiosurgical disorders. The father of pathological anatomy, Giovanni Battista Morgagni (1682-1771), had started his regular autopsy studies because he was not happy with the unexplainable physical signs and symptoms, and wanted to reveal the overlying biological process leading to disturbance of the human organism. Although anatomical lessons had been performed before Morgagni as well, the systematic comparison of clinical symptoms with morphological findings graduated him as a dedicated master of clinical pathology.

The term of radiosurgery signifies any kind of single application of ionizing radiation energy, in experimental biology or clinical medicine, aiming at the precise and complete destruction of chosen target structures containing healthy and/or pathological cells, without significant concomitant or late radiation damage to adjacent tissues [3]. Therefore, the goal of radiosurgical pathology should be to study the short- and long-term effects of high-dose ionizing radiation on neural tissue and its pathologies with histological, electron-microscopical, tissue culture and biological-biochemical methods. Radiosurgical pathology focuses its scope and microscope for histological, cell, genetic and molecular changes in the human body and experimental animals, or in tissue cultures and other in vitro experiments, generated by the ionizing radiation delivered from radiosurgical devices.

\section{Historical Antecedents}

The first human anatomical image collection was created by the great humanist, artist and scientist Leonardo da Vinci (1452-1519) as early as the 15 th century (fig. 1a, b). However, from a medical point of view, systematic anatomical lessons were performed by Andreas Vesalius (1514-1564) one century later. His experience was based totally on human autopsy studies and collected it in the book 'De humani corporis fabrica libri septem' published in 

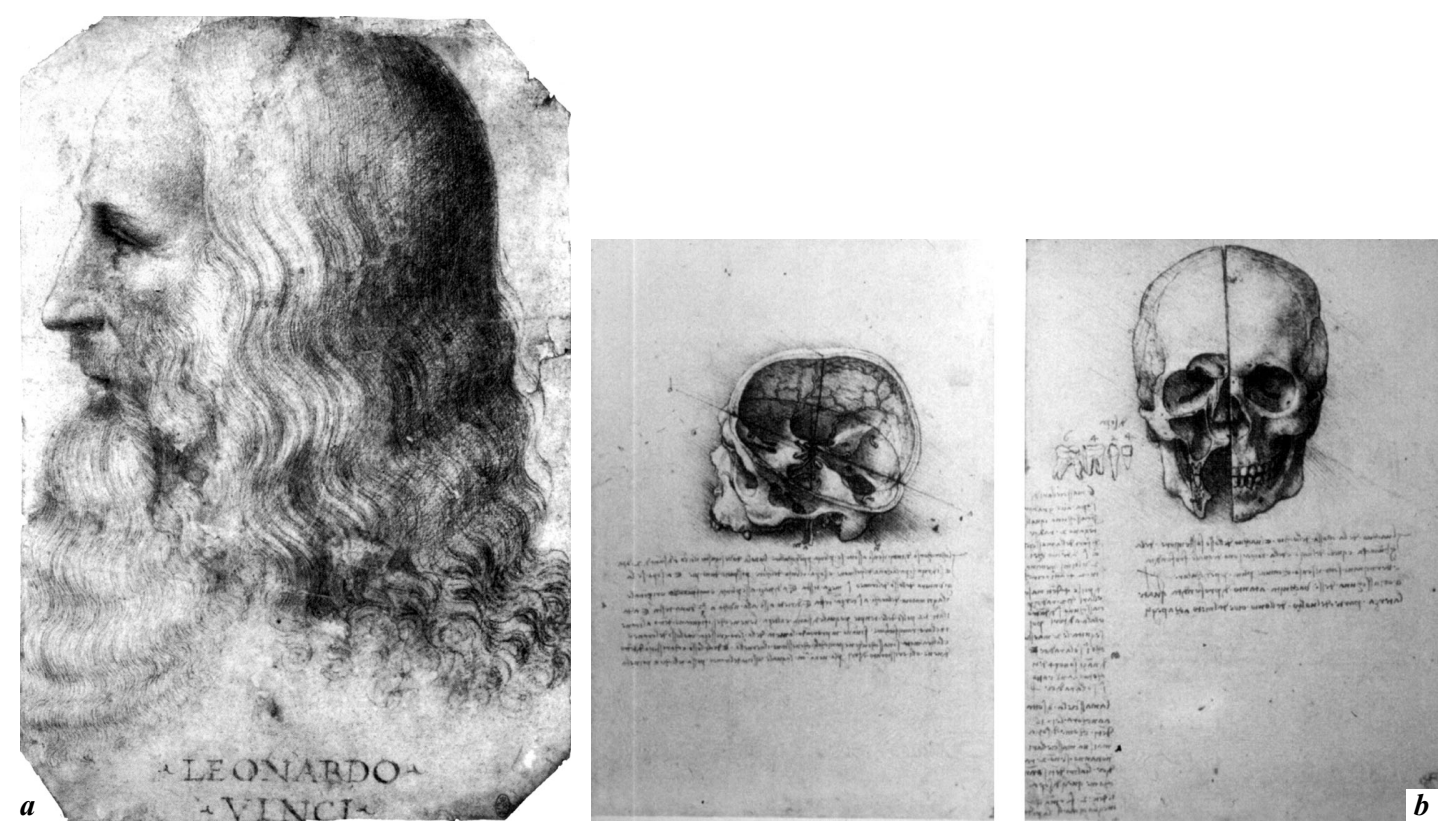

Fig. 1. $\boldsymbol{a}$ Portrait of Leonardo da Vinci (1452-1519). $\boldsymbol{b}$ Skull delineation from Leonardo's anatomical image collection.

1543 (fig. 2). In this way the anatomical teachings of Galenos, which came mainly from animal investigations, was developed. Another century ahead, and Giovanni Battista Morgagni (1682-1771), professor of medicine in Padova, Italy, started to collate on a regular basis clinical symptoms and signs with anatomical alterations in the human organism. He explained different disorders as consequences of morphological disturbances in the structure of organs therefore we can regard him as the founder of clinical pathology (fig. 3). His fundamental work 'De sedibus et causis morborum per anatomen indagatis libri quinque' was published in 1761. Antonie van Leeuwenhoek (1632-1723) did a meaningful contribution by the use of microscope for scientific investigations. The pioneer of microscopic anatomy was Marcello Malpighi (1628-1694) with regular histological examinations of various organs. Different tissue elements of the organism were discovered by Marie Françoise Xavier Bichat (1771-1802). He suggested that diseases propagate along tissues and established modern histology. An outstanding observation in structural research came from Mathias Jakob Schleiden (1804-1881) and Theodor Schwann (1810-1882). They realized that the cell is the basic unit of every living organism in 1838. Since then, the humoral pathophysiological theory was changed for the cellular approach. 


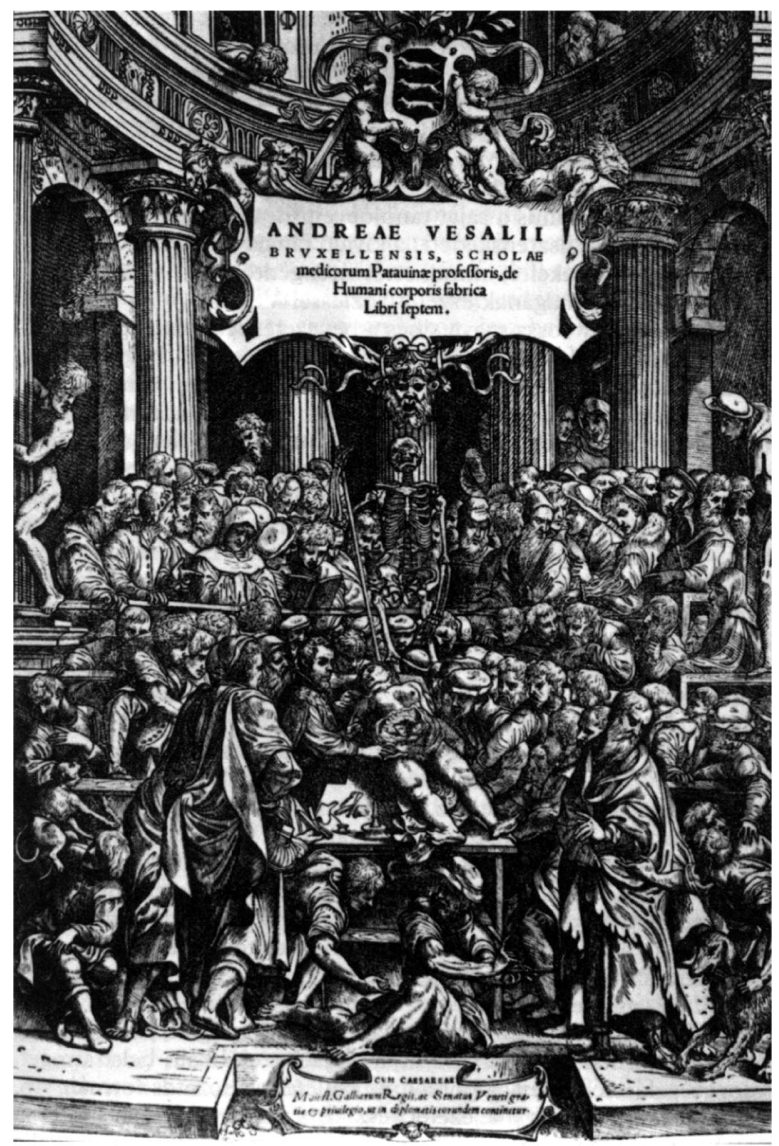

Fig. 2. The front page of Vesalius' anatomical book (1543).

The earliest Japanese anatomical studies were found in the books of Zoshi (1754) and the Kaitai Shinsho (1774). Two centuries later, in 1958, and the basic histopathological lesion in radiosurgery was published by Larsson and Leksell's group [4] in Nature. In that landmark paper they stated that in animal experiments 'with high-energy protons a sharply delimited lesion can be made at any desired site in the central nervous system.'

\section{Pathological Fundamentals}

The basic histopathological radiolesion created by high-energy ionizing radiation in neural tissue is a coagulation necrosis (fig. 4). This can be found 


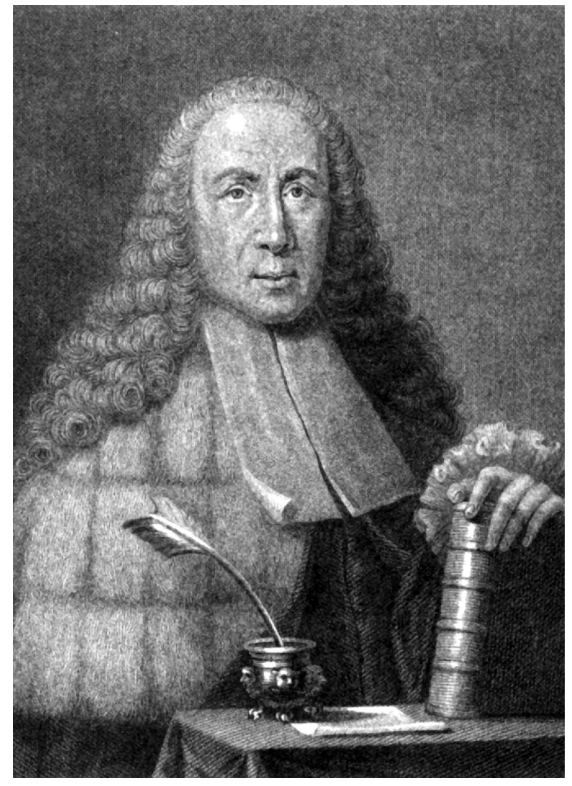

Fig. 3. Giovanni Battista Morgagni, the father of pathology (1682-1771).

within the target volume, it did not change in time, and the boundary between the necrosis and the surrounding structures is distinct, according to the sharp radiation fall-off [4-8]. Lesions appeared in the spinal cord following irradiation with doses of 400 and $200 \mathrm{~Gy}$ on the 3rd and 9th day respectively. They were sharply defined and had about the same width as the beam. In the cerebral hemispheres the earliest lesions were observed 14 days after irradiation with $200 \mathrm{~Gy}$, and the changes between 2 and 8 weeks were similar. Macroscopically, corresponding to the path of the beam, a groove appeared on the upper surface, and a sharply defined narrow band of discoloration was seen beneath the hemispheres. Histologically, within the lesion necrosis of nerve cells, myelin sheaths and axons occurred. Small perivenous hemorrhages were present at the margin of the lesions, and occasionally in the center of the damaged tissue, particularly in the gray matter. Collections of lymphocytes were seen in the necrotic zone and around it proliferation of astrocytes. These were the early experimental pathological changes following high-dose irradiation. In human brain the morphology of radiolesions were similar. The late histological changes were characterized by macrophages and calcium concrements in the necrotic centers of gamma radiolesions, surrounded by a wall with astrocytic proliferation. There were also round cell infiltration and congested capillaries around the lesion. Steiner et al. [9] have demonstrated that at least $140 \mathrm{~Gy}$ was necessary to produce a lesion in the human brain after radiosurgery. 


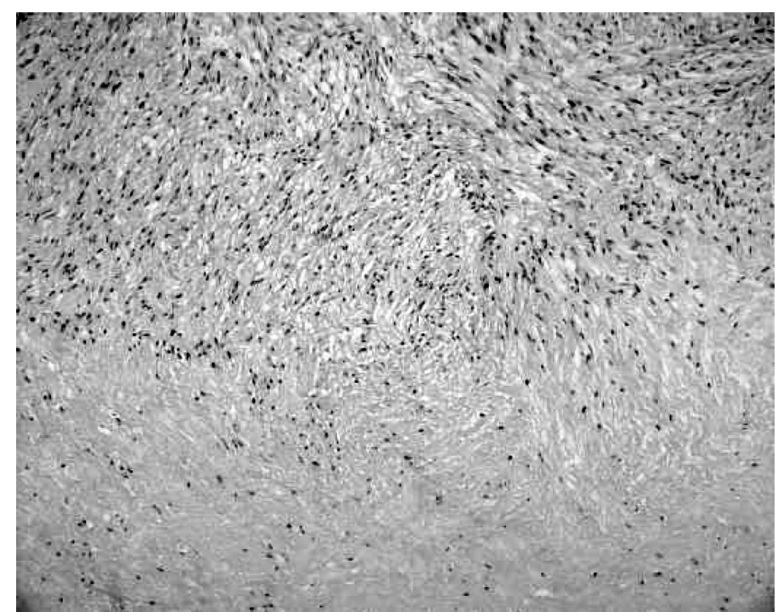

Fig. 4. Sharply demarcated gamma-radiolesion (i.e. coagulation necrosis) towards surrounding tissue. HE. $\times 200$.

With more than 160 Gy the lesions were consistently observed, and the optimal dose appeared to be around 170-180 Gy. Higher doses, up to $250 \mathrm{~Gy}$, did not change the physical characteristics of the lesion, which was due to the sharp dose gradient.

The pathological effect of radiosurgical interventions on the central nervous system tissue can reflect in degenerative and proliferative changes as well. Endothelial cell injury, apoptosis, coagulation necrosis and hyaline degeneration are the most frequent degenerative processes. These might be the result of cytotoxic effect of radiosurgery. They play important role in the destruction of malignant tumors, or normal tissue structures in functional neurosurgery $[10,11]$. On the other hand, granulation tissue formation, proliferation of fibrocytes, fibroblasts, myofibroblasts, capillaries or other vascular elements, inflammatory cells and production of collagen fibers appear as commonest proliferative responses after radiosurgery. This is the pathological situation mostly in the obliteration process of arteriovenous malformations [12-17]. Radiosurgery seems to cause a proliferative vasculopathy within the blood vessels of an AVM that begins with endothelial cell injury [18]. It appears that the abnormal vessels of neoplasms or vascular malformations have a relative sensitivity to radiosurgery in comparison to normal surrounding vessels [19]. Kondziolka et al. [20] believe that the radiobiological effect on meningiomas, schwannomas, pituitary tumors, and other benign neoplasms is a combination of both cytotoxic and delayed vascular effects. This observation was supported by further investigations [21]. 


\section{Quo vadis?}

Is radiosurgical pathology a new subspeciality? Do we need it? We think that we are at the beginning of a long and interesting road. Our purpose is to collect and process systematically potential radiosurgical pathology cases. That is, to follow all those cases where a radiosurgical intervention had been done as a first step, then the patient underwent an open conventional craniotomy-related operation or autopsy for some reason. We have to compare imaging data, treatment parameters, modern functional methods [22, 23], follow-up material with surgical pathology or autopsy macroscopical and histological findings. Results of experimental pathology should be included and considered as well [24-28]. In this way, systematic comprehensive and comparative investigations could become part of the broader radiobiology concept that would draw our attention and direct our activity towards radiosurgical pathology.

\section{Conclusions}

'Mortui vivos docent' was the original intention of pathology. Our hope is that radiosurgical pathology will promote better understanding of morphological changes, biological and pathophysiological mechanisms behind therapeutic radiosurgical interventions. In this way it would serve more sophisticated treatment planning of current and future potential radiosurgical disorders for the benefit of our patients in need.

\section{Acknowledgments}

Dr. Szeifert was supported by the Hungarian Health Scientific Society (ETT) grant 12980-9/2003-1018EKU; 395/KO/03. Parts of this study were funded by a grant from Congress of Neurological Surgeons and Elekta Instruments, Inc.

\section{References}

1 Leksell L: Cerebral radiosurgery. I. Gammathalamotomy in two cases of intractable pain. Acta Chir Scand 1968;134:585-595.

2 Kondziolka D, Lunsford LD, Witt TC, Flickinger JC: The future of radiosurgery: Radiobiology, technology and applications. Surg Neurol 2000;54:406-414.

3 Larsson B: Radiobiological fundamentals in radiosurgery; in Steiner L, Lindquist C, Forster D, Backlund EO (eds): Radiosurgery: Baseline and Trends. New York, Raven Press, 1992.

4 Larsson B, Leksell L, Rexed B, Sourander P, Mair W, Andersson B: The high-energy proton beam as a neurosurgical tool. Nature 1958;182:1222-1223. 
5 Leksell L, Larsson B, Andersson B, Rexed B, Sourander P, Mair W: Lesions in the depth of the brain produced by a beam of high-energy protons. Acta Radiol 1960;54:251-264.

6 Larsson B, Leksell L, Rexed B: The use of high-energy protons for cerebral surgery in man. Acta Chir Scand 1963;125:1-7.

7 Wennerstrand J, Ungerstedt U: Cerebral radiosurgery. II. An anatomical study of gamma radiolesions. Acta Chir Scand 1970;136:133-137.

8 Andersson B, Larsson B, Leksell L, Mair W, Rexed B, Sourander P, Wennerstrand J: Histopathology of late local radiolesions in the goat brain. Acta Radiol Ther Phys Biol 1970;9: 385-394.

9 Steiner L, Forster D, Leksell L, Meyerson BA, Boëthius J: Gammathalamotomy in intractable pain. Acta Neurochir 1980;52:173-184.

10 Szeifert GT, Salmon I, David P, Devriendt D, De Smedt F, Rorive S, Brotchi J, Levivier M: Tumor control and growth in a patient with two cerebral metastases treated with the Leksell Gamma Knife; in Kondziolka D (ed): Radiosurgery. Basel, Karger, 2002, vol 4, pp 152-161.

11 Szeifert GT, Massager N, Brotchi J, Levivier M: Morphological redifferentiation in a malignant astrocytic tumor after gamma knife radiosurgery. J Neurosurg 2002;97(suppl 5):627-630.

12 Yamamoto M, Jimbo M, Kobayashi M, Toyoda C, Ide M, Tanaka N, Lindquist C, Steiner L: Long-term results of radiosurgery for arteriovenous malformation: Neurodiagnostic imaging and histological studies of angiographically confirmed nidus obliteration. Surg Neurol 1992;37:219-230.

13 Yamamoto M, Jimbo M, Ide M, Kobayashi M, Toyoda C, Lindquist C, Karlson B: Gamma knife radiosurgery for cerebral arteriovenous malformations: An autopsy report focusing on irradiationinduced changes observed in nidus-unrelated arteries. Surg Neurol 1995;44:421-427.

14 Szeifert GT, Kemeny AA, Major O, Timperley WR, Forster DMC: Histopathological changes in cerebral arteriovenous malformations following stereotactic irradiation with the gamma knife; in Kondziolka D (ed): Radiosurgery 1997. Basel, Karger, 1998, vol 2, pp 129-136.

15 Szeifert GT, Kemeny AA, Timperley WR, Forster DMC: The potential role of myofibroblasts in the obliteration of arteriovenous malformations after radiosurgery. Neurosurgery 1997;40:61-66.

16 Szeifert GT, Vandersmissen B, Taib NOB, Balériaux D, Rodesch G, Salmon I, Brotchi J, Levivier M: Recurrent hemorrhage in a radiosurgically obliterated cerebral arteriovenous malformation; in Kondziolka D (ed): Radiosurgery. Basel, Karger, 2002, vol 4, pp 34-41.

17 Szeifert GT, Salmon I, Balériaux D, Brotchi J, Levivier M: Immunohistochemical analysis of a cerebral arteriovenous malformation obliterated by radiosurgery and presenting with re-bleeding. Case report. Neurol Res 2003;25:718-721.

18 Schneider BF, Eberhard DA, Steiner LE: Histopathology of arteriovenous malformations after gamma knife radiosurgery. J Neurosurg 1997;87:352-357.

19 Szeifert GT, Major O, Fazekas I, Nagy Z: Effects of radiation on cerebral vasculature: A review. Neurosurgery 2001;48:452.

20 Kondziolka D, Lunsford LD, Flickinger JC: The radiobiology of radiosurgery. Neurosurg Clin North Am 1999;10:157-166.

21 Szeifert GT, Massager N, Devriendt D, David P, De Smedt F, Rorive S, Salmon I, Brotchi J, Levivier M: Observation of intracranial neoplasms treated with gamma knife radiosurgery. J Neurosurg 2002;97(suppl 5):623-626.

22 Levivier M, Wikler D, Goldman S, David P, Metens T, Massager N, Gerosa M, Devriendt D, Desmedt F, Simon S, Van Houtte P, Brotchi J: Integration of the metabolic data of positron emission tomography in the dosimetry planning of radiosurgery with the gamma knife: Early experience with brain tumors. J Neurosurg 2000;93(suppl 3):233-238.

23 Levivier M, Wikler D, Goldman S, Massager N, Szeifert GT, David P, Devriendt D, Desmedt F, Simon S, Van Houtte P, Brotchi J: Positron emission tomography-guided radiosurgery: Early experience with the integration of metabolic data in the dosimetry planning with the Leksell Gamma Knife; in Kondziolka D (ed): Radiosurgery. Basel, Karger, 2002, vol 4, pp 123-133.

24 Major O, Kemeny AA, Forster DMC, Walton L, Szeifert GT: Time modulation effect of taxol on vasoreactivity of rat middle cerebral artery after single dose gamma irradiation; in Kondziolka D (ed): Radiosurgery 1997. Basel, Karger, 1998, vol 2, pp183-196.

25 Kondziolka D, Couce M, Niranjan A, Maesawa S, Fellows W: Histology of the 100-Gy thalamotomy in the baboon; in Kondziolka D (ed): Radiosurgery. Basel, Karger, 2002, vol 4, pp 279-284. 
26 Liscak R, Vladyka V, Novotny J Jr, Brozek G, Namestkova K, Mares V, Herynek V, Jirak D, Hayek M, Sykova E: Leksell gamma knife lesioning of the rat hippocampus: The relationship between radiation dose and functional and structural damage. J Neurosurg 2002;97(suppl 5): 666-673.

27 Major O, Szeifert GT, Radatz MWR, Walton L, Kemeny AA: Experimental stereotactic gamma knife radiosurgery. Vascular contractility studies of the rat middle cerebral artery after chronic survival. Neurol Res 2002;24:191-198.

28 Major O, Szeifert GT, Fazekas I, Dusan V, Csonka É, Kocsis B, Bori Z, Kemeny AA, Nagy Z: Effect of a single high-dose gamma irradiation on cultured cells in human cerebral arteriovenous malformation. J Neurosurg 2002;97(suppl 5):459-463.

Marc Levivier, MD, PhD

Centre Gamma Knife, Université Libre de Bruxelles

Hôpital Erasme, Route de Lennik 808

BE-1070 Brussels (Belgium)

Tel. +32 2 5553174, Fax +32 2 5553176, E-Mail Marc.Levivier@ulb.ac.be 